\title{
Creativity, visual literacy and information and communications technology
}

\author{
Avril M. Loveless \\ University of Brighton, Falmer, Brighton, BN19PH, UK. a.m.loveless@brighton.ac.uk
}

Keywords: ICT, visual literacy, artists, pedagogy, art curriculum

\begin{abstract}
ICT can be a catalyst for an interaction between practising artists, learners and teachers facing the challenges of developing pedagogy appropriate to new aspects of subject knowledge. This paper focuses on the ways the wider community can make a contribution to the ongoing curriculum, and provide insights into how ICT can extend the cultural experiences of children. It addresses some questions about the contribution of ICT to children's learning in the visual arts when artists bring their knowledge, understanding and practice into and beyond the school environment.
\end{abstract}

\section{FOREWORD}

"It is my view that the production of powerful and meaningful art work is made possible through a long term development of ideas and their visual representation. It is the representation of meaning that is the key that elevates production to a position beyond the merely decorative. My experience as an image maker has led me to conclude that this is achieved by entering into a 'dialogue' with the work. By dialogue, I mean the dynamic and creative cognitive processes involved when encoding and decoding meaning in visual texts. The meanings encoded are not necessarily known completely before a piece is produced. A powerful piece of work simultaneously represents less and more than the artist intends. The meaning and its representation in a visual form resolve themselves through a working method - a dialogue where the maker produces and the work responds. This takes time and a continuation of intention and cannot be achieved by ad hoc projects based on mechanical processes." (Taylor, 1998)

\footnotetext{
The original version of this chapter was revised: The copyright line was incorrect. This has been corrected. The Erratum to this chapter is available at DOI: 10.1007/978-0-387-35499-6_29
} 


\section{INTRODUCTION}

Our young people perceive and use ICT as a cultural artefact in their world. Probing the potential involvement of the community in school education may also provide new insights into how ICT can change and extend the cultural experience of young people. This paper addresses some questions about the contribution that ICT can make to children's experience of the visual arts when digital artists bring their knowledge, understanding and practice into - and beyond - the school environment.

Children can be creators and collaborators with ICT - not just consumers and collectors of information. This is an exciting thought for teachers involved in the developments in the use of ICT in education, in which the UK National Grid for Learning claims to connect learners to a physical network, a resource network and a human network (DfEE 1997). Easy access to information does not automatically lead to learning - any more than the availability of educational TV programmes does not transform a couch potato into a scholar. As teachers, we need to explore and be explicit about, the ways we can help children become learners who use a wealth of resources to assist them in the construction of their own knowledge and understanding. We also need to think about how we can encourage children to be active learners, using ICT to represent ways of knowing which have not been available to them with other technologies.

In an Information Society, meanings are communicated in a range of media - from the presentation of the weather forecast, to the packaging of a breakfast cereal or the conventions of the animated cartoon. Visual literacy plays a key role in our ability to decode and encode meanings, both to establish communication and to express our ideas to others. In helping children to develop literacies appropriate to our modern society, we must provide them with informed choices about the media they select to explore and express their visual ideas. What might ICT contribute to developing a visual literacy which is creative and collaborative?

A busy teacher might well argue that the use of ICT in the visual arts is inappropriate in an overfull curriculum using hard pressed resources. The argument is not based on evidence of children's actual use of ICT in their informal learning and culture. An increasing number of children have access to multimedia computers at home and can use them in creative ways. Teachers and parents do not seem to know how their children use computers, videos and games. They express concerns about games or inappropriate material found on the Internet, yet have a laissez-faire approach to children's experience in a world which is not understood or mediated by adults (Sanger et al, 1997). Even when children have access to technology which enables them to make, save and display visual work, they 
often find themselves producing visual images or animations which are incomplete and lack an audience for the presentation, development or exhibition of work (Sefton-Green and Buckingham 1998).

Teachers and artists are in a position to provide a framework for children which gives them confidence and skills to extend the boundaries of their creative experience. They can offer opportunities to children to develop processes of visual literacy, practise techniques with different tools and resources, and provide a range of audiences, separated in time and space, communicating through electronic networks.

\subsection{Adding to children's experience of visual arts?}

ICT's contribution is through the medium, approaches to working and the display of work. Digital data can be considered as a distinctive medium for 'making marks with mathematics', contrasting with other media, such as paint, clay, textiles and photographic emulsions. It is early days for understanding the distinctive expressive qualities of this medium (Mitchell 1994; Loveless 1997). There are many possible approaches. Mimicking the techniques and processes of other tools can produce lively and interesting images. But the ability to take an image apart, manipulate it, merge it with other images or use elements of it as starting points for new ideas, opens up a range of processes not easily available to children using traditional media. The form in which the image is to be displayed will influence the ways in which the audience views and interacts with the image. The children have to make choices about the appropriate ways in which to show and share work from printers to Web pages.

\subsection{A contribution to developing visual literacy?}

Creative visual literacy can be described as a long term and tentative, development of dialogue between the artist and the work. This requires exploration, taking risks, engaging with new techniques and processes, taking time for evaluation and making the most of the unexpected. The characteristics of the digital can provide children with opportunities to develop this dialogue between maker and made. The provisionality of ICT enables them explore visual ideas, try things out, and re-work without the discouragement of 'spoiling'. Ideas can be saved, recalled and changed with a choice to delete previous ideas, or leave a trail of different images saved, to show how the ideas developed from the start. Nothing need be final, images can displayed and passed on to others to develop. The interactivity of ICT supports this exploratory way of working, giving feedback on the consequences of decisions and offering chances to undo, change or extend 
ideas and actions. ICT can enable the children to save complex images as digital information and communicate and exhibit their ideas in a variety of forms across space and time.

\subsection{ICT in the art curriculum}

ICT presents new challenges to teachers' understanding of subject knowledge in art in order to underpin the children's experience with focused learning intentions in a meaningful context. The National Curriculum for Art in England and Wales requires that students should develop visual literacy to communicate ideas, feelings and meanings; that they should be taught about the visual elements of pattern and texture, colour, line and tone, shape, form and space; that they should be given opportunities to explore and use a range of media working on a variety of scales and be able to respond to and evaluate art, including their own and others' work (DFE 1995). ICT offers opportunities to develop these in contrast with other media and offer unique processes and experiences.

\subsection{The role of the teacher}

Teachers need to reflect on teaching strategies and organisation to facilitate such learning and how these may contrast with more familiar strategies. The teacher plays a role in giving children access to wider audiences, whether by leading a critical discussion with peers at the end of the day, displaying work around the school, collaborating with children in other schools, or exhibiting work on the school website.

\subsection{Artists in residence}

What do artists bring to this situation in which children and teachers are encountering new learning experiences? How do they support teacher development in the nature of art as a subject, in the technical skills required, in the ways of working as individuals and with others, in the opportunities to share and develop work with an audience, and in the dynamic process of developing visual literacy as a dialogue between maker and made? The artist in residence can be stimulating, encouraging and provoking, bringing new ways of looking and working to be built upon by teachers, children and artists as a powerful learning experience for all. There is a danger that the work of artists, both in their own right and with children, takes place outside the classroom and its curriculum concerns, so not touching the development of teachers or learners. 


\section{TWO CASE STUDIES}

In each project the artists worked with ICT to exploit its potential to allow children to construct visual images; develop them immediately and dynamically; display them in a number of forms to different audiences and develop their ideas over time. Each project illustrates how the interaction between the learners, teachers, artist and ICT provoked debate about the purpose and practicalities of such activities in the classroom. These discussions highlight ways forward for children to use tools to help them express visual ideas in sophisticated ways and engage in ways of working which challenge the development of teachers' subject knowledge and pedagogical strategies.

\subsection{Access: The Brighton Media Arts Project}

This project for teacher development took place in three primary schools, where teachers had little experience of using ICT in their art work. A three day course was provided to meet and work with the artist, Terry Taylor; provide some technical training with the ICT resources and suggest ways forward in curriculum planning and classroom practice.

Terry's own work raised questions about notions of contrast and difference between the natural and the manufactured, using space and positioning in the images to create surprising, curious or seemingly impossible juxtapositions of elements of the image. The children were fascinated, drawn in by the prospect of meeting with a 'live' artist. The children's work developed in different ways, initially using traditional techniques and then developing the children's ideas using digital cameras and graphics software. What contribution did ICT make to the development of visual literacy in these activities?

In each activity the children came to a point where they needed to construct their own images. The themes were abstract and sometimes difficult for the children to express and they needed the opportunity to try out their ideas, discard those they did not like and develop those that came closer to that which they were trying to express. Using the digital camera they were able to 'frame' a picture which could be used to develop a more complex image. Viewing it on the computer screen, the children could make decisions about whether they had managed to capture some of their ideas in ways which could be worked upon, or whether they needed to go out to look for and construct another image.

The key issues raised related to the ways in which ICT enabled the children to develop a 'dialogue' between themselves and the images they were making. The interactivity, provisionality and capacity of ICT gave 
them opportunities to look at, think about, refine and evaluate their work with immediate feedback and reassurance that mistakes would not frustrate their ideas. The digital camera enabled the children and teachers to build upon work developed with photography in framing and capturing images from the immediate surroundings. The graphics software let them develop these images with their imagination, using the variety of tools to present their ideas in different forms. The digital medium provided access to techniques and effects which could not be produced easily with more traditional processes and resources.

\subsection{The Bristol Internet Project}

This project focused on features of ICT to enable children to collaborate with others in their creative work. The ICT facilities were simple to use, but the processes in which the children were able to engage were powerful. Two artists worked in two schools in different parts of the city, which has a multicultural population, but in which communities were sometimes isolated or confrontational. The children in the schools represented two different communities with little opportunity to meet and work together. One of the aims of the project was to use art and ICT to set up communication between the groups of six year old children who could work with each other over space and time to produce visual images.

In each school, the children talked with the artist about activities that they liked or would like to do - driving a racing car, flying, playing basketball or sleeping and reading. They worked in pairs to construct images of themselves acting out these activities, thinking about how they would present themselves and instructing their friends on how to frame and capture that image using a digital camera. The children were asked to use a simple graphics package to work on their image - changing colours or cutting out irrelevant backgrounds. Again, the features of ICT were used to support this creative process - constructing, developing and presenting visual ideas which conveyed meaning.

The next stage in the project took forward the presentation of these ideas. The images were attached to an email message, and sent to children in the other school, requesting that they look at the pictures, think about what the activities might be, develop and complete the pictures using a graphics package, and send back their ideas with another email. A boy who sent a picture of himself 'flying' over the camera, returned portrayed as Superman. Another child who sent a cut-out of himself in a contorted position, received a picture of himself jumping up to a basket ball hoop. The children at each end of the Internet link were able to communicate with each other through text and visual images, think about what their partner was trying to say to 
them, and respond by developing their visual ideas. They used straightforward graphics techniques to interpret and complete the pictures from painting, drawing, cutting, and pasting, to using the 'dropper' to pick up and use a subtle range of colours from the clothes of the child in the picture.

ICT made two particular, unique contributions to the collaboration. The first was the ease, speed and informality of the communication over the Internet, covering gaps in space, time and culture. The second was the ways in which the children could alter and develop the piece itself, working with the digital medium to produce an image which was the result of more than one person's imagination, but leaving a trail of saved images which traced the development of ideas between those people.

Issues raised about the use of ICT in these activities related to both the unique facilities of the resources and the limitations imposed by the tools and techniques. The nature of the communication and exchange of ideas between the two groups of children were facilitated by the technology, from the digital cameras to the email links. Questions were raised about the 'origin' and 'ownership' of the shared images and the shifting roles of 'authors' and 'audiences' in such as activity. Some of the children, however, were disappointed by the clumsiness of the graphics tools.

\section{CONCLUSIONS}

Both projects demonstrated ways in which artists could work with children and teachers to contribute their expertise and experience to the art curriculum. They focused on meaningful ways for children to express and communicate their visual ideas to others. Within this context they used a range of media, techniques and processes to support and extend the children's capabilities. ICT features provided the children with a new medium for work, a range of techniques, an immediacy in the processes and the opportunity to explore, refine and express their visual ideas in creative and collaborative ways. ICT assisted the artists and teachers in setting up and maintaining a 'dialogue' between the children, their work and their audience and challenged the teachers to analyse the nature of this interaction and practice in order to develop their own pedagogy.

\section{REFERENCES}

DFE (1995) Art in the National Curriculum. London: Her Majesty's Stationery Office.

DfEE (1997) Connecting the Learning Society: National Grid for Learning. Consultation Paper. London: Department for Education and Employment.

Loveless, A. (1995) The Role of IT: Practical Issues for Primary Teachers. London: Cassell. 
Loveless, A. (1997) Working with images, developing ideas. In A. McFarlane, A. (ed.) Information Technology and Authentic Learning: Realising the Potential of Computers in the Primary Classroom. London: Routledge.

Mitchell, W.J. (1994) The Reconfigured Eye: Visual Truth in the Post-Photographic Era. Cambridge: MIT Press.

Sanger, J., Willson, J., Davies, B., and Whittaker, R. (1997) Young Children, Videos and Computer Games: Issues for Teachers and Parents. London: Falmer Press.

Sefton-Green, J. and Buckingham, D. (1998) Digital visions: Children's 'creative' uses of multimedia technologies. In Sefton-Green, J. (ed.) Digital Diversions. London: UCL Press

Taylor, T. (1998) The Access Project. An unpublished report to the Arts Council of England. UK: The University of Brighton.

\section{ACKNOWLEDGEMENTS}

Thanks to Terry Taylor, the artist working in the projects described, Access: The Brighton Media Arts Project was funded and supported by the Arts Council of England, the University of Brighton, South East Arts and Lighthouse, the Brighton Media Centre. The Bristol Internet Project was funded and supported by the Arts Council of England, Watershed Media Centre, Bristol, and Netgates Internet Service Provider, Bristol.

\section{BIOGRAPHY}

Avril Loveless is a Senior Lecturer in IT in Education at the University of Brighton, UK. She has taught in primary schools and worked as advisory teacher. Her research focuses on issues of culture, pedagogy and curriculum and the creative use of communication technologies. 